\title{
Co-localization and interaction of organic anion transporter 1 with caveolin-2 in rat kidney
}

\author{
Jin-Oh Kwak ${ }^{1}$, Hyun-Woo Kim ${ }^{1}$, \\ $\mathrm{K}$ wang-Jin $\mathrm{Oh}^{1}$, Dong Su Kim ${ }^{2}$,

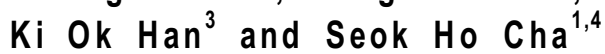 \\ ${ }^{1}$ Department of Pharmacology and Toxicology \\ ${ }^{2}$ Department of Dentistry \\ College of Medicine, Inha University \\ Incheon 400-712, Korea \\ ${ }^{3}$ Department of Medicine \\ Samsung Cheil Hospital and Women's Healthcare Centre \\ Sungkyunkwan University School of Medicine \\ Seoul 100-272, Korea \\ ${ }^{4}$ Corresponding author: Tel, 82-32-890-0957; \\ Fax, 82-32-890-0957; E-mail, shcha@inha.ac.kr
}

\section{Accepted 30 May 2005}

Abbreviations: Cav-2, caveolin-2; $\mathrm{CHO}$ cells, Chinese hamster ovary cells; FITC, fluorescein isothiocyanate; MTX, methotrexate; OAT1, organic anion transporter 1; ODN, oligodeoxynucleotide; $\mathrm{PAH}$, p-aminohippurate

\begin{abstract}
The organic anion transporters (OAT) have recently been identified. Although the some transport properties of OATs in the kidney have been verified, the regulatory mechanisms for OAT's functions are still not fully understood. The rat OAT1 (rOAT1) transports a number of negatively charged organic compounds between the cells and their extracellular milieu. Caveolin (Cav) also plays a role in membrane transport. Therefore, we investigated the protein-protein interactions between ROAT1 and caveolin-2. In the rat kidney, the expressions of rOAT1 mRNA and protein were observed in both the cortex and the outer medulla. With respect to Cav-2, the expressions of $m$ RNA and protein were observed in all portions of the kidney (cortex $<$ outer medulla $=$ inner medulla). The results of Western blot analysis using the isolated caveolae-enriched membrane fractions or the immunoprecipitates by respective antibodies from the rat kidney showed that rOAT1 and Cav-2 co-localized in the same fractions and they formed complexes each other. These results were confirmed by performing con-
\end{abstract}

focal microscopy with immunocytochemistry using the primary cultured renal proximal tubular cells. When the synthesized CRNA of rOAT1 along with the antisense oligodeoxynucleotides of Xenopus Cav-2 were co-injected into Xenopus oocytes, the $\left[{ }^{14} \mathrm{C}\right] \mathrm{p}$-aminohippurate and $\left[{ }^{3} \mathrm{H}\right] \mathrm{me}$ thotrexate uptake was slightly, but significantly decreased. The similar results were also observed in rOAT1 over-expressed Chinese hamster ovary cells. These findings suggest that rOAT1 and caveolin-2 are co-expressed in the plasma membrane and rOAT1's function for organic compound transport is upregulated by Cav-2 in the normal physiological condition.

Keywords: antisense oligodeoxynucleotide (ODN); caveolin-2 (Cav-2); organic anion transporter 1 (OAT1); renal proximal tubule

\section{Introduction}

The excretion of organic anions, including numerous endogenous and exogenous compounds is mainly performed in the kidney and liver. These organic anions (such as a number of clinically used drugs, pesticides and herbicides) are chemically heterogeneous substances that possess a carbon backbone and a net negative charge at physiological $\mathrm{pH}$. In the body, lipid-soluble compounds are biotransformed to their hydrophilic metabolites that are, in most cases, organic anions and many of them are harmful to the body. Therefore, their elimination is essential for the maintenance of homeostasis. In 1997, Sekine et al. and Sweet et al. (Sekine et al., 1997; Sweet et al., 1997) reported on the protein that contributed to the excretion of organic anions from rat kidney. The rOAT1 is a multispecific organic anion transporter that interacts with a variety of organic anions such as $p$-aminohippurate, $\beta$-lactam antibiotics, nonsteroidal anti-inflammatory drugs and diuretics (Sekine et al., 1997; Sweet et al., 1997). This transporter showed the identical transport characteristics of the classical organic anion transporter that is suggested on the basolateral membrane of the proximal tubule. Several lines of evidence have recently shown not only the expression of mRNA and protein, but also the regulation of the uptake function by many factors. Buist et al. have reported that the messenger RNA level of rat organic anion transporter 1 in the kidney of a gonadectomized and hypophysectomized rat was lowered with a treatment of growth hormone (Buist et 
al., 2003). The protein level of OAT1 was induced by chronic furosemide or hydrochlorothiazide infusion in rats (Kim et al., 2003). ERK1/2, when it was activated by epidermal growth factor and protein kinase $C$ up-regulated or down-regulated the its substrates uptake by OAT1, respectively (Wolff et al., 2003; Sauvant et al., 2004).

In recent decades, the caveolins (Cav) have also been reported as being important modulating molecules that bind some biologically active proteins. Caveolins are integral membrane proteins that are present in the caveolae, the small flask-shaped and detergent insoluble structures in the plasma membrane. Caveolins have been implicated in the vesicular transport processes and the transduction of the generated cellular receptors. Among the three caveolin isoforms, Cav-1 affects the function of many biologically important receptors and emzyme proteins (Couet et al., 1997; Lee et al., 2001; Schlegel et al., 2001; Liou et al., 2001; Jung et al., 2003; Cha et al., 2004; Jung et al., 2005). In addition, several transporter proteins are also anchored with and regulated by Cav-1 (McDonald et al., 1997; Bossuyt et al., 2002; Karlsson et al., 2002; Cai et al., 2004). In contrast to the extensive researches on Cav-1 or Cav-3, the study on the role of Cav-2 has been rather scant. Our previous studies on Cav-2's influence on some functional proteins (Jung et al., 2003; Cha et al., 2004) showed that Cav-2 also contributes to protein-protein interaction. Our previous study showed rOAT3 was bound to Cav-2 and regulated its function by Cav-2. When the amino acid sequence of rOAT1 was scanned, it also had caveolin-binding motifs similar to that of rOAT3.

Therefore, the purpose of this study was to investigate the protein-protein interaction between rOAT1 and caveolin-2. In addition, we also studied the regulatory effect of caveolin-2 in the function of rOAT1.

\section{Materials and Methods}

\section{Drugs and chemicals}

PCR primers, AMV reverse transcriptase $X L, T a q$ and LA-Taq DNA polymerase were purchased from TaKaRa Korea Biomedical Co. (Seoul, Korea). TRI reagent, transferrin, epidermal growth factor (EGF) and protein A-sepharose were purchased from Sigma-Aldrich (St. Louis, MO). Streptomycin, penicillin, Dulbecco's Modified Eagle's Medium (DMEM) and fetal bovine serum (FBS) were bought from Gibco BRL (Grand Island, NY). $\left[{ }^{14} \mathrm{C}\right] p$-aminohippurate and $\left[{ }^{3} \mathrm{H}\right]$ methotrexate were purchased from PerkinElmer Life Science Products (Boston, MA) and Moravec Biochemicals (Brea, CA). Polyclonal rabbit anti-rat OAT1 were purchased from Alpha Diagnostic International Inc. (San Antonio, TX). Monoclonal mouse anti-human caveolin-2, goat antimouse and anti-rabbit lgG:horseradish peroxidase antibodies were purchased from Transduction Laboratories (Lexington, MS). All other chemicals utilized in this study were of the highest purity available from commercial sources.

\section{RT-PCR analysis and CDNA construction of rOAT1}

Extraction of total RNA was conducted by using the TRI reagent according to the manufacturer's instructions. Isolated total RNA (500 ng) was reverse transcribed using $5 \mathrm{U}$ of AMV reverse transcriptase $\mathrm{XL}$ for $30 \mathrm{~min}$. The prepared cDNAs were employed as template for PCR. The condition for PCR was as follows; one cycle of $60 \mathrm{~s}$ at $94^{\circ} \mathrm{C}, 35$ cycles each for $30 \mathrm{~s}$ at $94^{\circ} \mathrm{C}, 30 \mathrm{~s}$ at $55^{\circ} \mathrm{C}$ and $90 \mathrm{~s}$ at $72^{\circ} \mathrm{C}$, and one cycle of $10 \mathrm{~min}$ at $72^{\circ} \mathrm{C}$. The PCR products $(15 \mu \mathrm{l})$ were then separated in a $1 \%$ agarose gel electrophoresis and stained with ethidium bromide. In order to obtain full sequence of rat OAT1, LA-Taq DNA polymerase was employed. PCR amplification was carried out with restriction enzyme site-linked primer (EcoR1 and Not1) set containing initiation and stop codon of rOAT1. The products of PCR were subcloned to a mammalian expression vector, pcDNA $3.1(+)$, and their sequences were confirmed by using Big-dye method. The sequences of used primer sets are shown in Table 1.

\section{Western blotting}

The separated renal cortical and medullary tissues and Xenopus laevis oocytes were homogenized in 9 volume of $2.1 \mathrm{M}$ sucrose solution containing 0.26 $\mathrm{U} / \mathrm{ml}$ aprotinin, $0.1 \mathrm{mM}$ phenylmethylsulfonyl fluoride, $10 \mu \mathrm{g} / \mathrm{ml}$ leupeptin, and $10 \mu \mathrm{g} / \mathrm{ml}$ trypsin inhibitor with a Teflon-glass tissue homogenizer, followed by centrifugation at $500 \mathrm{~g}$ for $5 \mathrm{~min}$. The resulting supernatant was recentrifuged at $8,000 \mathrm{~g}$ for $10 \mathrm{~min}$. The supernatants were then centrifuged at 100,000 $g$ for $1 \mathrm{~h}$, and the pellets containing crude membrane fractions were used to Western blotting. The protein samples were boiled for $10 \mathrm{~min}$ in sample buffer and subjected to $10 \%$ SDS-polyacrylamide gel electrophoresis. The separated proteins were transferred electrically onto a Hybond-P polyvinylidene difluoride transfer membrane (Amersham Pharmacia Biotech). The membrane was blocked for $1 \mathrm{~h}$ in $5 \%$ skimmilk-Tris-buffered saline (TBS; $20 \mathrm{mM}$ Tris/HCl $[\mathrm{pH}$ 7.0], and $150 \mathrm{mM} \mathrm{NaCl}$ ), washed with TBS, and then incubated with antibodies of rOAT1 $(1: 2,000)$ or Cav-2 $(1: 200)$ for $1 \mathrm{~h}$ at room temperature. After washing the membrane three times with TBS containing $0.1 \%$ Tween-20, the membrane was incubated for $1 \mathrm{~h}$ with the goat anti-rabbit or anti-mouse lgG: horseradish peroxidase antibody $(1: 3,000)$ at room temperature. After washing with TBS, the membrane was visualized by the ECL kit (Amersham Pharmacia Biotech. Buckinghamshire, UK).

\section{Cell culture}

Rat renal proximal tubular cells were primarily cultured from microdissected proximal tubule segments. The microdissection technique of nephron segments has been previously described (Cha et al., 1998). 
Microdissected tubules were incubated in a humidified atmosphere of $5 \% \mathrm{CO}_{2}$ in air at $37^{\circ} \mathrm{C}$. Basal medium was DMEM supplemented with $5 \%$ FBS, $10 \mu \mathrm{g} / \mathrm{ml}$ transferrin, $1 \mu \mathrm{g} / \mathrm{ml}$ insulin, $10 \mathrm{ng} / \mathrm{ml} \mathrm{EGF,} 100 \mathrm{U} / \mathrm{ml}$ penicillin $G$ sodium and $100 \mu \mathrm{g} / \mathrm{ml}$ streptomycin. The cells at third-passage were supplied to confocal microscopy.

\section{Confocal microscopy}

The primary cultured proximal tubular cells on cover slips were fixed with $4 \%$ para-formaldehyde solution in PBS ( $\mathrm{pH} 8.4 ; 15 \mathrm{~min}$, room temperature) and permeabilized by $0.1 \%$ Triton $\mathrm{X}-100$ solution in PBS (10 $\mathrm{min}$, room temperature). The nonspecific binding sites were blocked with $10 \%$ control serum in PBS for $30 \mathrm{~min}$ in room temperature. Polyclonal antibody of rOAT1 $(1: 2,000)$ and monoclonal antibodies of Cav-2 (1:50) were treated to the fixed cells for $1 \mathrm{~h}$. Secondary antibodies without prior antibody treatment were also included as controls. After washing, cells were double stained with fluorescein isothiocyanate (FITC)- and Texas Red-conjugated secondary antibodies for $30 \mathrm{~min}$. After washing, samples were examined both at the green and red wavelengths under a Bio-Rad MRC 1000 confocal microscope. More than 50 cells have been inspected per experiment and the photos of cells with typical morphology and staining are presented.

\section{Preparation of caveolae-enriched membrane fraction}

Caveolae-rich membrane fraction from rat kidney was fractionated using sucrose gradient ultracentrifugation (Liou et al., 2001). In brief, rat kidney was homogenized in $2 \mathrm{ml}$ of lysis buffer $(10 \mathrm{mM}$ Tris-HCL, $\mathrm{pH}$ 7.5, $150 \mathrm{mM} \mathrm{NaCl}, 5 \mathrm{mM}$ EDTA, $1 \mathrm{mM}$ phenylmethylsulfonyl fluoride, $10 \mu \mathrm{g} / \mathrm{ml}$ leupeptin, $10 \mu \mathrm{g} / \mathrm{ml}$ trypsin inhibitor, and $1 \%$ Triton $\mathrm{X}-100$ ) followed by sonication. The homogenate was brought to $40 \%$ sucrose by addition of an equal volume of $80 \%$ sucrose and loaded in an ultracentrifuge tube. A discontinuous sucrose gradient was layered on top of the sample by placing $4 \mathrm{ml}$ of $30 \%$ and $4 \mathrm{ml}$ of $5 \%$ sucrose, respectively. After centrifugation at 200,000 $g$ for $16-20 \mathrm{~h}$ at $4^{\circ} \mathrm{C}$, the upper light scattering band at the $5-30 \%$ sucrose interface was collected as the caveolin-rich fraction and the lower band $(40 \%$ sucrose layer) was collected as the non-caveolin fraction.

\section{Immuno-precipitation of rOAT1 and Cav-2}

The soluble lysate of rat kidney was incubated with antibodies specific for rOAT1, Cav-2 or a pre-immune rabbit $\lg G$ at a final concentration of $4 \mu \mathrm{g} / \mathrm{ml}$ for 4 $\mathrm{h}$ at $4^{\circ} \mathrm{C}$ (Kim et al., 2004). Protein-A-Sepharose was then added for $2 \mathrm{~h}$ at $4^{\circ} \mathrm{C}$. Thereafter, the samples were centrifuged and the pellets were washed 4 times with PIPA buffer $(150 \mathrm{mM} \mathrm{NaCl}, 1 \mathrm{mM}$ EDTA, $1 \%$ triton X-100, 1\% NP-40, 0.05\% SDS, and $10 \mathrm{mM}$ Tris;
$\mathrm{pH}$ 8.0) and then prepared for the Western blotting analysis by boiling in the sample buffer to determine whether interactive binding has occurred between Cav-2 and rOAT1.

\section{cRNA synthesis and uptake experiments using Xenopus laevis oocytes and rOAT1 overexpressed CHO cells}

cRNA synthesis and uptake measurements were performed as described previously (Cha et al., 2000). The capped cRNA was synthesized by in vitrotranscription using T7 RNA polymerase from the plasmid DNA linearized with Notl. Defolliculated oocytes were injected with $20 \mathrm{ng}$ of the capped rOAT1 cRNA with or without Xenopus Cav-2 scrambled or antisense oligodeoxynucleotides (ODN) and incubated in Barth's solution $(88 \mathrm{mM} \mathrm{NaCl}, 1 \mathrm{mM} \mathrm{KCl}, 0.33 \mathrm{mM}$ $\mathrm{Ca}\left(\mathrm{NO}_{3}\right)_{2}, 0.4 \mathrm{mM} \mathrm{CaCl}, 0.8 \mathrm{mM} \mathrm{MgSO} 4,2.4 \mathrm{mM}$ $\mathrm{NaHCO}_{3}$, and $10 \mathrm{mM} \mathrm{HEPES}$ ) containing $50 \mu \mathrm{g} / \mathrm{ml}$ gentamicin at $18^{\circ} \mathrm{C}$. After 2 to 3 days of incubation, $\left[{ }^{14} \mathrm{C}\right] \mathrm{p}$-aminohippurate or $\left[{ }^{3} \mathrm{H}\right] \mathrm{m}$ ethotrexate uptake experiments was performed at room temperature in ND96 solution (96 mM NaCl, $2 \mathrm{mM} \mathrm{KCl}, 1.8 \mathrm{mM}$ $\mathrm{CaCl}_{2}, 1 \mathrm{mM} \mathrm{MgCl}$ and $5 \mathrm{mM}$ HEPES, $\mathrm{pH} \mathrm{7.4)} \mathrm{as}$ described elsewhere (Cha et al., 2000). The antisense oligodeoxynucleotide sequences are also shown in Table 1.

The subcloned rOAT1 plasmids were co-transfected to $\mathrm{CHO}$ cells by LIPOFECTAMINE 2000 reagent. Confluent cells in $100 \mathrm{~mm}$ culture dish were washed twice with Opti-MEM and plasmids (30 $\mu \mathrm{g}$ for each) with/without caveolin antisense oligodeoxynucleotide were introduced to cells. After 1 day, cells were trypsinized and seeded $\left(5 \times 10^{5}\right.$ cells/well $)$ and grown

Table 1. Nucleotide sequences of used primers.

\begin{tabular}{llr}
\hline & \multicolumn{1}{c}{ Sequence } & Size \\
\hline rOAT1 & & \\
F & ATGGTGGTTGCTCCCCTACTGCTG & 398 \\
R & AGGTAGCCAACACCATGGCTCCC & \\
rOAT1 & & \\
F (EcoR1) & GCGCGCGAATTCATGGGCCTTCAATGACC 1682 \\
R (Not1) & GCGCGCGCGGCCGCCTAGCACGAGC & \\
Cav-2 & & 391 \\
F & ATGGGGCTGGAGACCGAGAAGG \\
R & ATCCAGATGTGCAGACAGCTGAGG \\
s-ODN & GGAGAGCCAGATACAACT \\
X. Cav-2 & & \\
a-ODN & AGTTGTATCTGGCTCTCC \\
rCav-2 & & \\
a-ODN & TCTTCACAAAAGGCATTAG
\end{tabular}

$F$, forward; $R$, reverse; s-ODN, scrambled-oligodeoxynucleotide; a-ODN, antisense-oligodeoxynucleotide; $X, X$ enopus; $r$, rat. 
in DMEM containing $10 \%$ FBS. For substrate uptake measurements, cells were used 2 days after plating (90-100\% confluence) on 24-well plates. Dulbecco's modified phosphate-buffered saline (Dulbecco's PBS) containing $\left[{ }^{14} \mathrm{C}\right] p$-aminohippurate or $\left[{ }^{3} \mathrm{H}\right]$ methotrexate was added after pre-incubation of the cells in Dulbecco's PBS for $10 \mathrm{~min}$ at $37^{\circ} \mathrm{C}$. The reaction was terminated by removing the uptake medium followed by washing three times with ice-cold Dulbecco's PBS. Then, the cells were solubilized with $0.1 \mathrm{~N} \mathrm{NaOH}$, and radioactivity was counted. Because $\left[{ }^{14} \mathrm{C}\right] p$-aminohippurate or $\left[{ }^{3} \mathrm{H}\right]$ methotrexate uptake was linearly dependent on the incubation time up to $5 \mathrm{~min}$, for all the experiments, uptakes were measured for 2 min (Chairoungdua et al., 1999).

\section{Statistical analysis}

Statistical analyses were performed using the ANOVA test for multiple comparison and a $P$ value $<0.05$ was considered significantly different.

\section{Results}

The expression pattern of rOAT1 and Cav-2 in the rat kidney

In order to determine the expressional pattern of rOAT1 and Cav-2 in the kidney, we performed RTPCR and Western blot analysis on separated rat renal cortical and medullary tissues. As shown in Figure 1, the strong expressions of rOAT1 mRNA and protein were observed in the cortex and outer medulla portions without any expression being observed in the inner medulla portion. In contrast to rOAT1, the expressions of Cav-2 mRNA and protein were observed

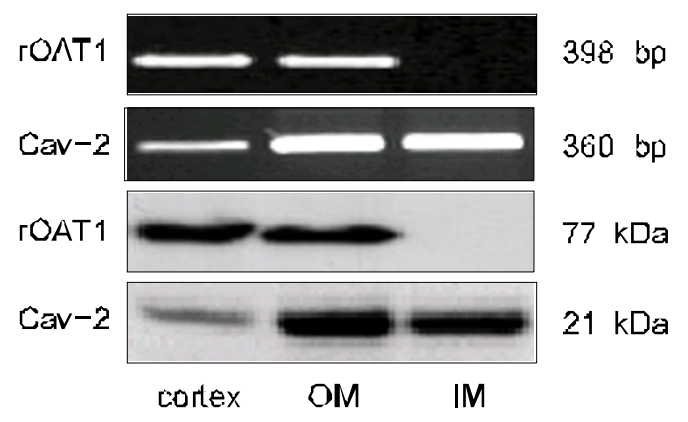

Figure 1. Expression of rOAT1 and Cav-2 (mRNAs and proteins) in rat renal tissue separated along the corticomedullary axis. Expression of rOAT1 mRNA was determined by employing RT-PCR ( 35 cycles). PCR products were separated on the $1 \%$ agarose gel by electrophoresis and detected with ethidium bromide staining. For expression of respective proteins, isolated membrane protein $(20 \mu \mathrm{g} / \mathrm{lane})$ was separated by electrophoresis on the $10 \%$ acryl amide gel and presence of each rOAT1 or Cav-2 was detected with respective rOAT1 $(1: 2,000)$ or Cav-2 $(1: 200)$ antibodies. Photographs represent the typical result from 3 independent experiments. to gradually increase along the corticomedullary axis. The order of intensity was cortex $<$ outer medulla = inner medulla.

\section{Western blot analysis using isolated membrane fraction and immunoprecipitates by respective antibodies in the rat kidney}

To confirm the localization of rOAT1 to caveolae, we prepared caveolae-rich membrane fractions from rat kidney and we analyzed the rOAT1 and Cav-2 proteins in these fractions by Western blot analysis. As shown in Figure $2 \mathrm{~A}$, both rOAT1 and Cav-2 proteins were observed predominantly in the detergentinsoluble fractions numbered 4 and 5 . To determine whether there is a direct binding between the rOAT1 and Cav-2, the lysates of rat kidney were initially immunoprecipitated with the antibodies directed against rOAT1 or Cav-2. The precipitates were subsequently electrophoresed by SDS-PAGE and the separated proteins were transferred to a membrane. The formation of a complex between the rOAT1 and Cav-2 was analyzed by Western blot analysis using designated antibodies. The rOAT1 or Cav-2 proteins did not precipitate with the control IgG (Figure 2B, designated none). As shown in Figure $2 \mathrm{~B}$, the presence of the rOAT1 and Cav-2 complex was detected upon precipitation with rOAT1 antibody (left panel). The presence of the rOAT1 and Cav-2 complex could also be detected following precipitation with Cav-2 antibody (right panel).

\section{Subcellular localization of rOAT1 and Cav-2 in the cultured renal proximal tubular cells}

To demonstrate the localization of rOAT1 and Cav-2 in the plasma membrane, we employed confocal microscopy using the cultured cells derived from the proximal tubules. The cells were treated with the antibodies to rOAT1 or Cav-2. Cells were double stained with two different secondary antibodies, one was conjugated with FITC (rOAT1) and the other was conjugated with Texas Red (Cav-2), respectively. The green fluorescent rOAT1 stain was localized to the plasma membrane (Figure $3 \mathrm{~A}$ ) and the red fluorescent Cav-2 stain detected in the plasma membrane and cytosol (Figure 3B). The overlaid image showed the co-localization of rOAT1 with Cav-2 (Figure 3C). Non-specific staining by the secondary antibodies was not observed (Figure 3D and E). When we examined 50 cells, above $70 \%$ of the tested cells showed a similar pattern.

\section{Effect of Cav-2 on the uptake function of rOAT1 in Xenopus oocytes and rOAT1 overexpressed CHO cells}

We have constructed full-length cDNA of rOAT1 by RT-PCR using the RNA isolated from cortex and outer medulla tissues of rat kidney. It was subcloned to the mammalian expression vector pcDNA $3.1(+)$ 
$\mathbf{A}$

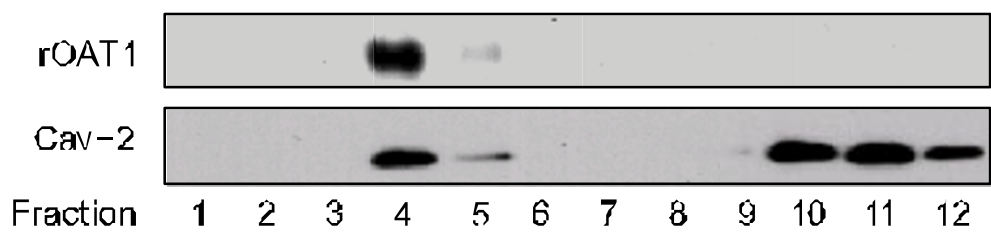

No.

B

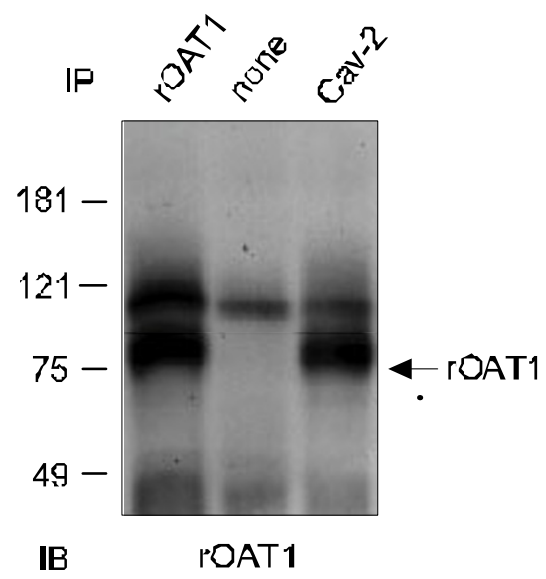

Figure 2. Western blot analysis using isolated membrane fraction and immunoprecipitates by antibodies in the rat kidney. (A) The kidneys were lysed using a Teflon/ glass homogenizer and a sonicator, and subjected to sucrose gradient centrifugation as described under Materials and Methods. Equal amounts of protein $(10 \mu \mathrm{g})$ from each of twelve fractions (1-12) were separated by SDS-PAGE 15\% acrylamide gel and transferred to membranes, which were blotted using anti-rOAT1 antibody $(1: 2,000)$ and anti-Cav-2 (1:200). Obtained data from 2 separate experiments were consistent. (B) Cell lysates were immuno-precipitated initially with antibodies of rOAT1 or Cav-2 and the respective immuno-precipitated (IP) proteins $(15 \mu \mathrm{g})$ were loaded onto each lane of a $10 \%$ SDSpolyacrylamide gel. Kidney lysate was immuno-precipitated initially with rOAT1 (left pannel) and was immuno-precipitated initially with Cav2 antibodies (right pannel). $\mathrm{Ob}$ tained data from 2 separate experiments were consistent. (sequencing data not shown). To determine the effect of Cav-2 on $\left[{ }^{14} \mathrm{C}\right] p$-aminohippurate $(\mathrm{PAH})$ or $\left[{ }^{3} \mathrm{H}\right]$ methotrexate (MTX) uptakes by rOAT1 in a Xenopus oocyte expression system, Xenopus Cav-2 scrambled and antisense ODN were employed. There was no change in the viability of oocytes among the groups injected with water, with rOAT1 CRNA, with rOAT1 cRNA + scrambled ODN or with rOAT1 cRNA + antisense ODN. As shown in Figure 4A, protein expression of rOAT1 by CRNA of rOAT1 was not changed by the co-injection of X. Cav-2 scrambled or antisense ODN. There was no change on Cav-2 expression by co-injection of Cav-2 scrambled ODN. In contrast, Cav-2 protein expression was decreased by the co-injection of Cav-2 antisense ODN. The PAH and MTX uptakes in the rOAT1 cRNA-injected oocytes showed a high uptake rate compared with that of the water-injected oocytes (designate as a control). The amount of PAH or MTX uptakes in the rOAT1 cRNA injected oocytes were $112.0 \pm 9.0$ $\mathrm{pmol} /$ oocyte $/ \mathrm{h}$ and $332.1 \pm 23.0 \mathrm{fmol} /$ oocyte $/ \mathrm{h}$, respectively (Figure 4B). When scrambled ODN was injected with rOAT1 CRNA, the uptake rates of PAH or MTX were slightly changed but not significant. To demonstrate the effect of Cav-2 on the function of rOAT1, we designed antisense ODN in the open reading frame of Xenopus Cav-2. The uptake rates of PAH or MTX in the Cav-2 antisense ODN coinjected oocytes (10 pmol/oocyte) with rOAT1 cRNA (20 ng/oocytes) decreased about $30 \%$ and $45 \%$, respectively. When used rOAT1 overexpressed $\mathrm{CHO}$ cells, the similar results were observed (Figure 4C).

\section{Discussion}

The present study describes the protein-protein interaction between ROAT1 and caveolin-2. The results indicate that rOAT1 is co-localized at the plasma membrane and this is combined with at least some portion of caveolin-2. The uptake function of rOAT1 is up-regulated by caveolin-2 under normal physiological conditions.

Caveolin-1 (Cav) is the first reported structural protein of the caveolae. The caveola are small $(60-100$ $\mathrm{nm}$ diameter) clathrin-free invaginations at the surface of most peripheral cells. A multigene family of caveolin-related proteins has been recently identified (Okamoto et al., 1998). Cav-2 having a $58 \%$ similarity to Cav-1 has an overlapped tissue distribution with caveolin-1. Cav-3 is muscle-specific and it has a similar function to Cav-1. Several membrane associated signaling molecules are known to contain a common amino acid sequence motif (i.e., $\phi X \phi X X X X \phi$ or $\phi X X X X$ $\phi X X \phi$, in which $\phi$ designates aromatic amino acids like Trp (W), Phe (F) or Tyr $(Y)$ and $X$ can be any amino acids) that recognizes scaffolding domains present in the caveolins. The functions of these signal molecules in the caveolae are generally known to down-regulate or to up-regulate by binding to the caveolins via the scaffolding domains.

A scan of the rat OAT1 primary amino acid sequence indicated that there are five potential caveolinbinding motifs located at amino acids 109-116, 228$235,259-267,346-354$ and 442-449. One caveolinbinding motif is located at an extracellular site (109- 

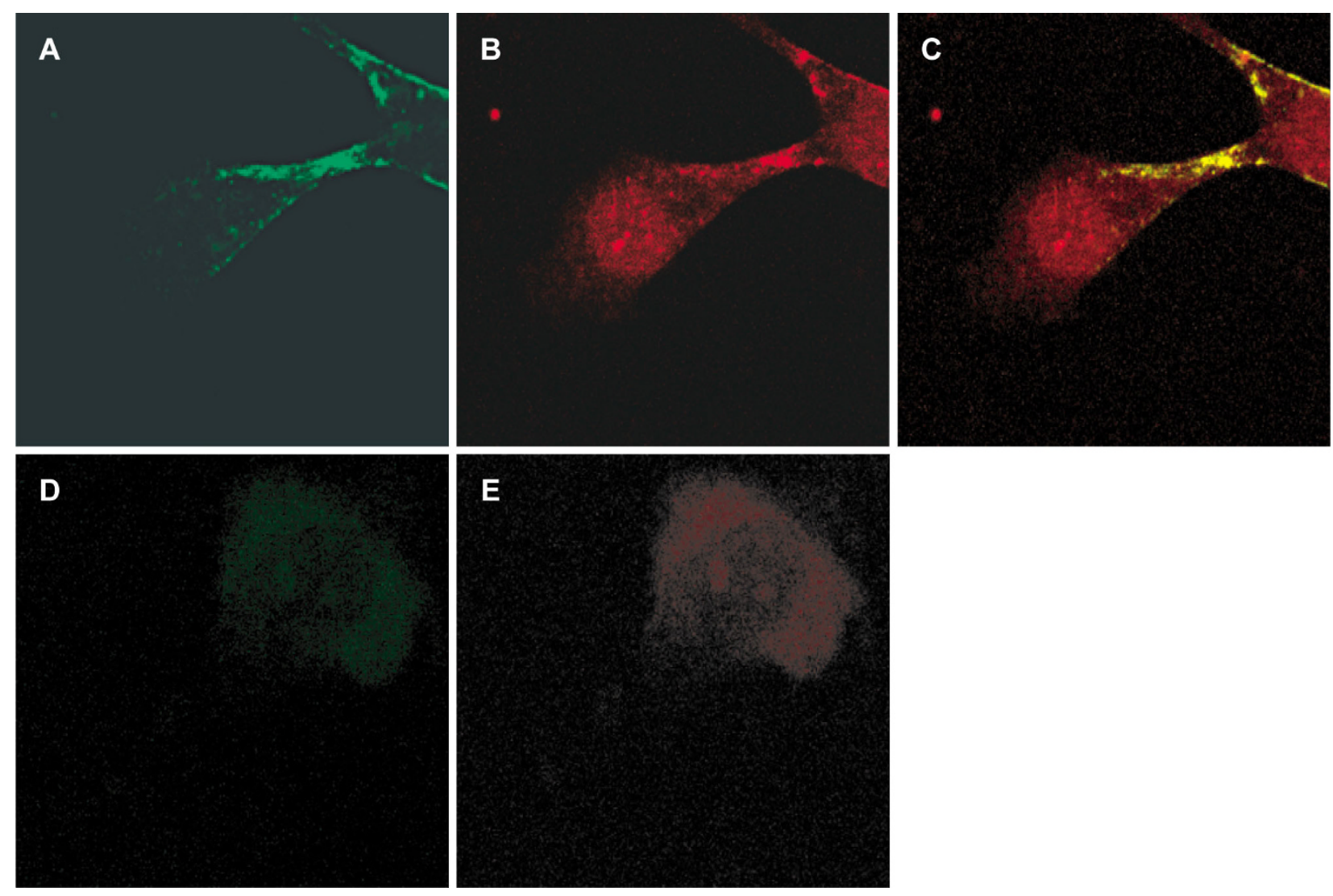

Figure 3. Confocal microscopy of renal proximal tubule-derived primary cultured cells immuno-cytochemically stained with rOAT1 and Cav-2 antibodies. Cells were double stained with fluorescein isothiocyanate- and Texas Red-conjugated secondary antibodies after an initial treatment with either rOAT1 or Cav-2 antibodies separately and then examined under a confocal microscope at their respective wavelengths. For each experiment, at least 50 cells were examined and the presented images represent typical staining pattern for the majority of examined cells. A, rOAT1; B, Cav-2; C, merged images of $A$ and $B$. D and E, stained only with secondary antibodies without the prior treatment of either rOAT1 or Cav-2 antibodies to show the images of non-specific bindings.

116), three motifs are located within the putative membrane spanning domain $(228-235,346-354$ and 442-449), and one motif is located at or near the cytoplasmic face of the plasma membrane (259-267). Considering the transmembrane structure, one motif (259-267) is thought to be a candidate for the caveolin-binding site. Molecular in vitro mutagenesis experimentation will be necessary to confirm the specific binding site in rOAT1.

The previous studies using Northern blot analysis with the mRNA isolated from the total kidney tissue did not indicate the expression of any caveolins, but some recent studies that used the glomerular mesangial cells or renal proximal tubule cells showed the expression of Cav-2 (Tamai et al., 2001; Zager et al., 2002; Jung et al., 2003; Cha et al., 2004). Therefore, as the first step of this study, we determined the expressions of rOAT1 and Cav-2 (mRNA and protein) in the kidney along the corticomedullary axis. Both the mRNA and protein expressions of rOAT1 were detected in the cortex and outer medulla without any expression in the inner medulla. These results well agreed with previously reported results (Sekine et al., 1997; Kojima et al., 2002). While the expressions of Cav-2 mRNA and protein were observed in all portions of the kidney. The order of the expression intensity was inner medulla $=$ outer medulla $>$ cortex. Because the kidney is an organ having many receptors related to intracellular signal transduction, although it is not absolute, the distributions of the functional proteins along the nephron were in good agreement with the caveolin expression when the relationships between caveolin and the signaling molecules were considered.

It is well known that Cav-2 or rOAT1 are integral membrane proteins. Confocal microscopy using primary cultured renal proximal tubule-derived epithelial cells well supports this fact; at least some portion of these proteins are co-localized in the plasma membrane in a bound form and some portion of Cav-2 are also distributed in the cytosol. This finding on the distribution of Cav-2 is in good agreement with the results of Mora and coworkers (1999). This was also confirmed by Western blot analysis using the caveo- 
A
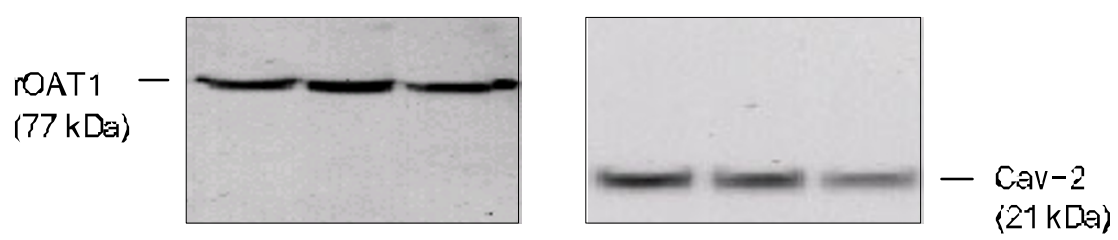

B
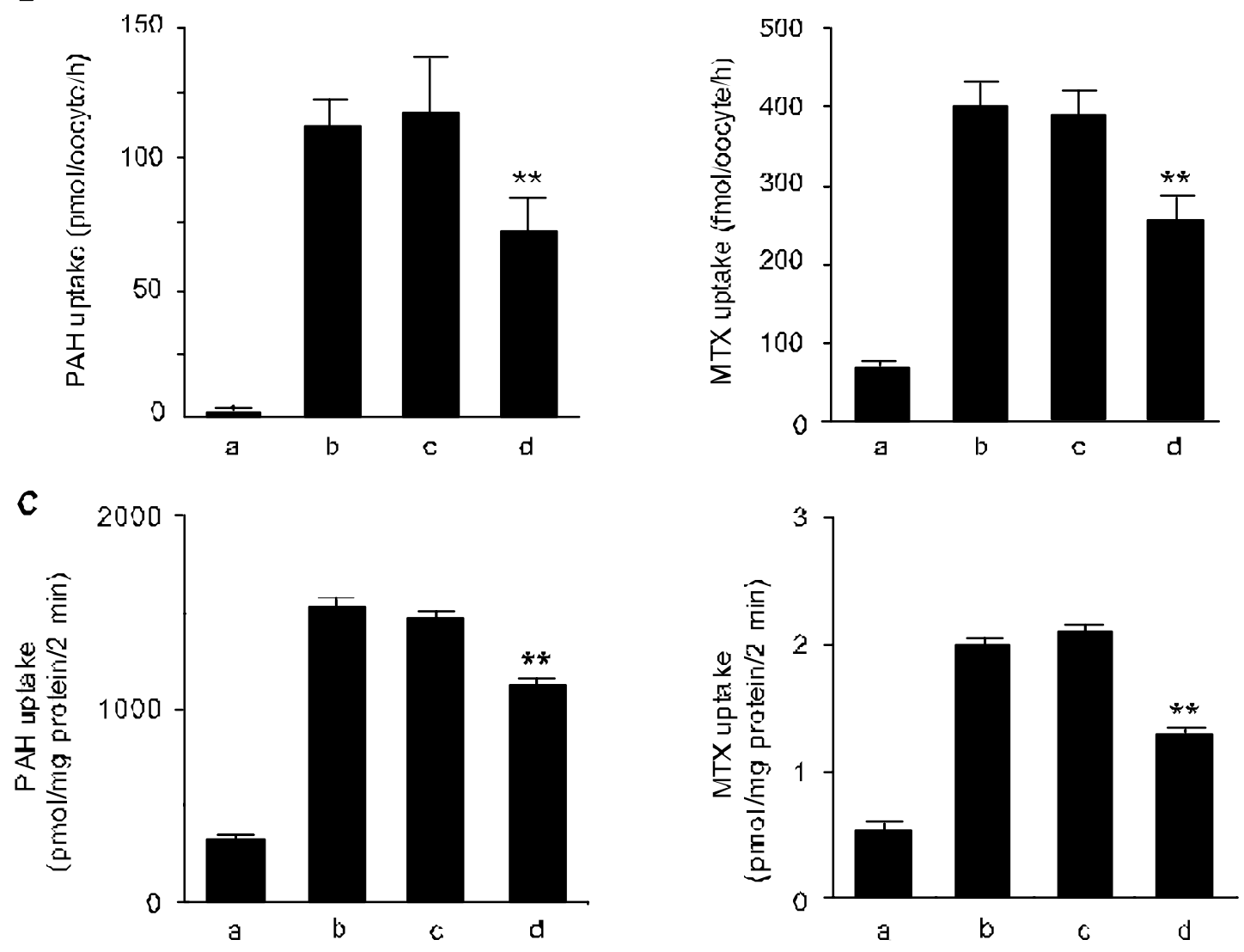

Figure 4. The effects of scrambled- or antisense-oligodeoxynucleotides on rOAT1-mediated PAH or MTX uptake in Xenopus laevis oocyte and eukaryotic cell expression system. (A) The expression of rOAT1 and Cav-2 proteins in ROAT1 CRNA injected oocytes. Membrane protein was extracted 50 rOAT1 CRNA injected oocytes and Western blot analysis was performed. (B) Defolliculated stage $\mathrm{VI}$ and $\mathrm{V}$ oocytes were injected water, rOAT1 CRNA (20 ng/oocyte) with/without senese or antisense ODN (10 pmol/oocyte). After 3 days, $\left[^{14} \mathrm{C}\right] \mathrm{PAH}(20 \mu \mathrm{M})$ or $\left[^{3} \mathrm{H}\right] \mathrm{MTX}(2 \mu \mathrm{M})$ uptake were determined for $1 \mathrm{~h}$. (C) $\left.{ }^{14} \mathrm{C}\right] \mathrm{PAH}(20 \mu \mathrm{M})$ or $\left[^{3} \mathrm{H}\right] \mathrm{MTX}(2 \mu \mathrm{M})$ uptake in rOAT1 transfected $\mathrm{CHO}$ cell. Uptake was performed for $2 \mathrm{~min}$. Each bar represents the mean \pm standard error for three independent experiments. Each experiment contains 8-10 oocytes and three wells. PAH, p-aminohippurate; MTX, Methotrexate; **, $P<0.01$ compared with control. a, control; b, rOAT1 injected or transfected; $c$, scramble ODN co-injected or transfected; $d$, antisense ODN co-injected or transfected.

lae-rich membrane fraction isolated from rat kidney. In addition, the results of the immuno-precipitation experiment showed the formation of a complex between rOAT1 and Cav-2. These results strongly suggest that caveolin may act on the function of the rOAT1 protein in the plasma membrane. In order to demonstrate the functional relationship between Cav-2 and rOAT1, we performed uptake experiments using Xenopus scrambled or Cav-2 antisense ODNs in a Xenopus oocyte and overexpressed cell expression systems. Therefore, we primarily tested the expression of Cav-2 and
ROAT1 protein in rOAT1 cRNA injected Xenopus oocytes. The spontaneous Cav-2 mRNA and protein expressions and the rOAT1 protein expression via the injection of cRNA were observed. Although there were no detectable changes of the rOAT1 protein expression by the co-injection of Cav-2 scrambled or antisense ODNs, the Cav-2 expression was decreased by the co-injection of Cav-2 antisense ODN. The increases of PAH or MTX uptake rates by rOAT1 were significantly inhibited with the co-injection of antisense ODN with rOAT1 CRNA, but not with the 
injection of scrambled ODN with rOAT1 cRNA. The similar result also was obtained using different expression system (rOAT1 transfected cell system). These results strongly suggest that Cav-2 up-regulates the function of rOAT1 under normal physiological conditions.

There are a number of reports on the functional regulation of the organic anion transporters. The rOAT1 contains multiple potential phosphorylation sites in the intracellular loop between the transmembrane domains 6 and 7 , and also in the carboxyl terminus. The presence of these conserved phosphorylation sites suggested that OAT might be subject to phosphorylation-induced functional regulation. You and co-workers (You et al., 2000) have shown the involvement of reversible phosphorylation in regulating the function of mOAT1. Okadaic acid, a protein phosphatase inhibitor, significantly increased the level of mOAT1 phosphorylation and it enhanced the phophorylation in a dose-dependent and time-dependent manner that was closely correlated to the decreased $\mathrm{PAH}$ transport. The serine phosphorylation sites in OAT1 are acted on by protein kinase $C$ (PKC) and casein kinase II. It has been shown that PKC activation leads to the decreased transport of organic anions (Uwai et al., 1998; Lu et al., 1999; You et al., 2000).

Jayanthi and co-workers have recently shown that PKC activation by the phorbol esters down-regulates the norepinephrine transporter activity without any substrate affinity by the process of internalization (Qian et al., 1997; Apparsundaram et al., 1998a and 1998b; Jayanthi et al., 2004). In addition, Wolff and co-workers have also demonstrated that PKC activation by $s n$-1,2-dioctanoylglycerol and $4 \alpha$-phorbol12-myristate-13-acetate down-regulates the human organic anion transporter 1-mediated transport by carrier internalization and not by the involvement of phosphoryration of the predicted classic OAT1-PKC consensus sites (Wolff et al., 2003). It is interesting that the candidate caveolin-binding motif FIAFIYSWF is located near the transmembrane domain 6 (amino acid 259-267) and the PKC site is closely located in the same neighborhood (amino acid 271, 278, and 284). With this information, we could establish a hypothetical scheme for the down-regulation of OAT1's function by PKC activation. PKC activation by certain stimuli may cause the phosphorylation of the caveolin. This may induce internalization of caveolae with OAT1 protein anchored with caveolin, and the functional activity of rOAT1 is also sequentially downregulated.

In conclusion, we report here on the protein-protein interaction of rOAT1 and caveolin-2. Some portions of rOAT1 and caveolin-2 are co-localized in the caveolae of the plasma membrane to form a proteinprotein complex. The substrate uptake function of rOAT1 is up-regulated by caveolin-2 under normal physiological conditions. In the near future, it will be necessary to investigate both the regulatory mechanism of caveolin-2 on the caveolin phosphorylation and the interaction of rOAT1 with the other caveolin isoforms. Information from our present study might give some important clues on the pathological and/or physiological causes for drug sensitivities of renal disorder patients.

\section{Acknowledgement}

This work was supported by the grant from Korea Research Foundation Grant (KRF-2003-041-E00087).

\section{References}

Apparsundaram S, Galli A, DeFelice LJ, Hartzell HC, Blakely $\mathrm{RD}$. Acute regulation of norepinephrine transport: I. protein kinase C-linked muscarinic receptors influence transport capacity and transporter density in SK-N-SH cells. J Pharmacol Exp Ther 1998;287:733-43

Apparsundaram S, Schroeter S, Giovanetti E, Blakely RD. Acute regulation of norepinephrine transport: II. PKC-modulated surface expression of human norepinephrine transporter proteins. J Pharmacol Exp Ther 1998;287:744-51

Bossuyt J, Taylor BE, James-Kracke M, Hale CC. Evidence for cardiac sodium-calcium exchanger association with caveolin-3. FEBS Lett 2002;511:113-7

Buist SC, Cherrington NJ, Klaassen CD. Endocrine regulation of rat organic anion transporters. Drug Met Dispos 2003;31:559-64

Cai C, Zhu H, Chen J. Overexpression of caveolin-1 increases plasma membrane fluidity and reduces P-glycoprotein function in Hs578T/Dox. Biochem Biophys Res Commun 2004;320:868-74

Cha SH, Sekine T, Endou H. P2 purinoceptor localization along rat nephron and evidence suggesting existence of subtypes P2Y1 and P2Y2. Am J Physiol 1998;274:F1006-14

Cha SH, Jung NH, Kim BR, Kim HW, Kwak JO. Evidence for cyclooxygenase-1 association with caveolin-1 and -2 in cultured human embryonic kidney (HEK 293) cells. IUBMB Life 2004;56:221-7

Cha SH, Sekine T, Kusuhara H, Yu E, Kim JY, Kim DK, Sugiyama $Y$, Kanai $Y$, Endou $H$. Molecular cloning and characterization of multispecific organic anion transporter 4 expressed in the placenta. J Biol Chem 2000;275:4507-12

Chairoungdua A, Segawa H, Kim JY, Miyamoto K, Haga $H$, Fukui $Y$, Mizoguchi $K$, Ito $H$, Takeda E, Endou $H$, Kanai $Y$. Identification of an amino acid transporter associated with the cystiuia-related type II membrane glycoprotein. J Biol Chem 1999;274:28845-8

Couet J, Li S, Okamoto T, Ikezu T, Lisanti MP. Identification of peptide and protein ligands for the caveolin-scaffolding domain. Implications for the interaction of caveolin with caveolae-associated proteins. J Biol Chem 1997;272:6525-33

Jayanthi LD, Samuvel DJ, Ramamoorthy S. Regulated internalization and phosphorylation of the native norepinephrine transporter in response to phorbol esters. Evidence for localization in lipid rafts and lipid raft-mediated internalization. J Biol Chem 2004;279:19315-26 
Jung $\mathrm{NH}$, Kim HP, Kim BR, Cha SH, Kim GA, Ha H, Na YE, Cha YN. Evidence for heme oxygenase-1 association with caveolin-1 and -2 in mouse mesangial cells. IUBMB Life 2003;55:525-32

Jung SY, Kwak JO, Kim HW, Kim DS, Ryu SD, Ko CB, Cha $\mathrm{SH}$. Calcium sensing receptor forms complex with and is up-regulated by caveolin-1 in cultured human osteosarcoma (Saos-2) cells. Exp Mol Med 2005;37:91-100

Karlsson M, Thorn H, Parpal S, Stralfors P, Gustavsson J. Insulin induces translocation of glucose transporter GLUT4 to plasma membrane caveolae in adipocytes. FASEB $\mathrm{J}$ 2002;16:249-51

Kim GH, Na KY, Kim SY, Joo KW, Oh YK, Chae SW, Endou $\mathrm{H}$, Han JS. Up-regulation of organic anion transporter 1 protein is induced by chronic furosemide or hydrochlorothiazide infusion in rat kidney. Nephrol Dial Transplant 2003;18:1505-11

Kim J, Min G, Bae YS, Min DS. Phospholipase D is involved in oxidative stress-induced migration of vascular smooth muscle cells via tyrosine phosphorylation and protein kinase C. Exp Mol Med 2004;36:103-9

Kojima R, Sekine T, Kawachi M, Cha SH, Suzuki Y, Endou $\mathrm{H}$. Immuno-localization of multispecific organic anion transporters, OAT1, OAT2, and OAT3, in rat kidney. J Am Soc Nephrol 2002;13:848-57

Lee H, Woodman SE, Engelman JA, Volonte D, Galbiati F. Palmitoylation of caveolin-1 at a single site (Cys-156) controls its coupling to the c-Src tyrosine kinase: targeting of dually acylated molecules (GPI-linked, transmembrane, or cytoplasmic) to caveolae effectively uncouples c-Src and caveolin-1 (TYR-14). J Biol Chem 2001;276:35150-8

Liou JY, Deng WG, Gilroy DW, Shyue SK, Wu KK. Colocalization and interaction of cyclooxygenase-2 with caveolin-1 in human fibroblasts J Biol Chem 2001;276:34975-82

Lu R, Chan BS, Schuster VL. Cloning of the human kidney PAH transporter: Narrow substrate specificity and regulation by protein kinase C. Am J Physiol 1999;276:F295-303

McDonald KK, Zharikov S, Block ER, Kilberg MS: A caveolar complex between the cationic amino acid transporter 1 and endothelial nitric-oxide synthase may explain the "arginine paradox". J Biol Chem 1997;272:31213-6

Mora R, Bonilha VL, Marmorstein A, Scherer PE, Brown D, Lisanti MP, Rodriguez-Boulan R. Caveolin-2 localizes to the golgi complex but redistributes to plasma membrane, caveolae, and rafts when co-expressed with caveolin-1. J Biol Chem 1999;274;25708-17
Okamoto T, Schlegel A, Scherer PE, Lisanti MP. Caveolins, a family of scaffolding proteins for organizing "preassembled signaling complexes" at the plasma membrane. J Biol Chem 1998;273:5419-22

Qian Y, Galli A, Ramamoorthy S, Risso S, DeFelice LJ, Blakely $\mathrm{RD}$. Protein kinase $\mathrm{C}$ activation regulates human serotonin transporters in HEK-293 cells via altered cell surface expression. J Neurosci 1997;17:45-57

Sauvant C, Hesse D, Holzinger H, Evans KK, Dantzler WH, Gekle M. Action of EGF and PGE2 on basolateral organic anion uptake in rabbit proximal renal tubules and hOAT1 expressed in human kidney epithelial cells. Am J Physiol 2004;286;F774-83

Schlegel A, Wang C, Pestell RG, Lisanti MP. Ligand-independent activation of oestrogen receptor alpha by caveolin-1. Biochem J 2001;359:203-10

Sekine T, Watanabe N, Hosoyamada M, Kanai Y, Endou H. Expression cloning and characterization of a novel multispecific organic anion transporter. J Biol Chem 1997;272: 18526-29

Sweet DH, Wolff NA, Pritchard JB. Expression cloning and characterization of ROAT1: The basolateral organic anion transporter in rat kidney. J Biol Chem 1997;272:30088-95

Tamai O, Oka N, Kikuchi T, Koda Y, Soejima M, Wada Y, Fujisawa M, Tamaki K, Kawachi $H$, Shimizu F, Kimura $H$, Imaizumi T, Okuda $S$. Caveolae in mesangial cells and caveolin expression in mesangial proliferative glomerulnephritis. Kidndy Int 2001;59:471-80

Uwai Y, Okuda M, Takami K, Hashimoto Y, Inui K. Functional characterization of the rat multispecific organic anion transporter OAT1 mediating basolateral uptake of anionic drugs in the kidney. FEBS Lett 1998;438:321-4

Wolff NA, Thies K, Kuhnke N, Reid G, Friedrich B, Lang $F$, Burckhardt $G$. Protein kinase $C$ activation downregulates human organic anion transporter 1-mediated transport through carrier internalization. J Am Soc Nephrol 2003;14: 1959-68

You G, Kuze K, Kohanski RA, Amsler K, Henderson S. Regulation of mOAT-mediated organic anion transport by okadaic acid and protein kinase C in LLC-PK(1) cells. J Biol Chem 2000;275:10278-84

Zager RA, Johnson A, Hanson S, Rosa VD. Altered cholesterol localization and caveolin expression during the evolution of acute renal failure. Kidney Int 2002;61:1674-16 